\title{
A Large-Scale Quantitative Survey of the German Geocaching Community in 2007
}

\author{
Daniel Telaar, ${ }^{1}$ Antonio Krüger, ${ }^{2}$ and Johannes Schöning ${ }^{3}$ \\ ${ }^{1}$ University of Münster, Germany \\ ${ }^{2}$ German Research Center for Artificial Intelligence, Saarbrücken, Germany \\ ${ }^{3}$ Hasselt University-tUL-iMinds, Diepenbeek, Belgium \\ Correspondence should be addressed to Johannes Schöning; johannes.schoening@uhasselt.be
}

Received 10 February 2014; Revised 12 May 2014; Accepted 9 June 2014; Published 26 June 2014

Academic Editor: Francesco Bellotti

Copyright (C) 2014 Daniel Telaar et al. This is an open access article distributed under the Creative Commons Attribution License, which permits unrestricted use, distribution, and reproduction in any medium, provided the original work is properly cited.

\begin{abstract}
We present a large-scale quantitative contextual survey of the geocaching community in Germany, one of the world's largest geocaching communities. We investigate the features, attitudes, interests, and motivations that characterise the German geocachers. Two anonymous surveys have been carried out on this issue in the year 2007. We conducted a large-scale qualitative general study based on web questionnaires and a more targeted study, which aimed at a comprehensive amount of revealed geocaches of a certain region. With sample sizes of $n=1982$ (study 1: general study) and $n=310$ (study 2: regional study) we provide a representative basis to ground previous qualitative research in this domain. In addition, we investigated the usage of technology in combination with traditional paper-based media by the geocachers. This knowledge can be used to reflect on past and future trends within the geocaching community.
\end{abstract}

\section{Preamble}

This work presents a study of the geocaching community in Germany in the year 2007. We are aware that there are 7 years between the data collection and the date of the publication. This paper reports on a contextual survey of the geocaching community in Germany in 2007. Geocaching as an activity has moved a lot since 2007. On January 9th 2007, Steve Jobs announced the first generation of iPhone and Microsoft did the same for Windows Vista. Technology has moved a lot as well.

We strongly advise to read this paper in the context of technology of the year 2007 and also interpret the results in this context. The results presented in the body of this paper will be different today. The core contribution of this paper is that it presents a large scale quantitative contextual survey of the geocaching community in Germany in the year 2007 and in the context of 2007. We see its value as a broad overview and insights of the geocaching community and the geocaching activity in general and provide an additional historic data point. We hope our findings can be useful for other researchers in this area, especially in combination and relationship with other related works from various years. For example our study of the geocaching community in 2007 was followed up with many other researchers in the field of HCI, for example, by the work of Matherson et al. [1] and O'Hara [2] in 2008 and the work of Gram-Hansen [3] in 2009, followed by Lochrie et al. [4], Zan et al. [5], and Lund et al. [6] in 2010 and some recent works of Bowser et al. [7] and Vartiainen and Tuunanen [8] in 2013 and Procyk et al. [9] in 2014.

The studies reported later in this paper outperform other user studies in terms of quantity and are different in terms of methodology. In the spirit of criticisms of Greenberg and Buxton [10] we believe that our work also provides data to verify and deepen findings of the sort that O'Hara [2] and Chavez et al. [11] and others have presented previously. We believe that the HCI community should be aware of this data set; even it reports data from 2007. It is an important piece to have a complete historic picture on the geocaching activity from a HCI perspective.

\section{Introduction and Motivation}

The activity of geocaching was attracting attention both in terms of activity of geocachers and from researchers that 
identify the act of geocaching as an interesting example of a location-based service that still have a high popularity as shown by O'Hara [2]. To date, location-based and pervasive games have mostly been studied in rather artificial conditions, where the participants have been asked to use research prototypes as reported by various researchers including [1216]. What is so interesting in geocaching is that the activity itself relies on an appropriation of a location-based service, namely, the most basic service of all, a simple positioning service provided by a Global Positioning System (GPS) device. This makes geocaching an emerging cultural behaviour, which has not been designed from any central authority. According to O'Hara [2] geocaching is an interesting study area for the LBS community, because "as a technologyenabled location-based activity, it has various attributes that make it significant to understand both in itself but also to inform our more general understanding of locationbased computing practices." Interestingly the growth rates are massively shrinking these days, even more people have smartphones that could run geocaching applications. It therefore provides a very good role model for technology centric activity that now enters a different stage on the life cycle. O'Hara identifies three interesting properties of geocaching.

(1) First, it is a location-based experience that has established and sustained itself over several years (starting in 2000).

(2) It involves both the consumption and the creation of experiences.

(3) It is a game that uses extensively virtual and physical representations and involves a mobile device.

While [2] is the first investigation that tries to address the motivations and interests of geocachers, it could not address the community as a whole, given the qualitative nature and low number of participants in the study. In this paper we exploit the three attributes mentioned by O'Hara with two user studies. Currently a bit more than $10 \%$ of all geocaches are located in Germany. By attaching questionnaires both by placing them very prominently on various web pages and discussion forums (general study) and to the digital representations of caches (regional study), we have managed to reach out to a large part of Germany's geocaching community. In the two studies we have conducted, we have managed to obtain more than 2200 valid online questionnaires, which have helped us to draw representative conclusions on the structure of the German geocaching community. To our knowledge this is the first attempt to analyse a large community in the area of location-based services and our work provides data to verify and deepen findings of the sort that others $[2,11,17]$ have presented previously. The contributions presented in this paper are as follows:

(i) the results of two large user studies conducted with over 2000 participants (which is about 10 times more data points than in comparable studies),

(ii) a report on the motivations and interests of large groups of geocachers, (iii) also informing our more general understanding of location-based computing practices and

(iv) and, by sharing this dataset with other researchers, preserving it to later be able to generate an accurate historic picture over the changes in the geocaching community in the last decade covering all different stages of the development of the activity.

The following section briefly summarizes the history and origin of geocaching. We also describe some basis geocache types and sizes later used in the studies to understand what kinds of geocaches users are targeting at and find attractive. Related work is presented in the next section. This is followed by a description of two users studies we conducted. Section 4 presents the results of both studies. A discussion of the findings is given in Section 5. Finally, we present our conclusions and ideas for future work in the last section.

2.1. History and Status Quo of Geocaching. On May 1st, 2000, the amount of error of the selective availability (SA) GPS signal, that can introduce random errors of up to a hundred meters, was "set to zero" as reported by [18]. This allowed the more precise localisation for civil and scientific purpose using GPS and it was also the birthday of geocaching. One day after the shut-down of the SA, Dave Ulmer posted the main idea of geocaching in an internet newsgroup (The group can be found under sci.geo.satellite-nav): "it should be easy to find someone's stash from waypoint information. Waypoints of secret stashes could be shared on the internet; people could navigate to the stashes and get some stuff. The only rule for stashes is the following: Get some Stuff, Leave some Stuff!!!" Ulmer's post is still available online in the newsgroup and still today internet forums and website are the key source for the geocaching community to store and communicate the locations of caches. On the next day he buried a first "stash" (containing a log book, a map of the area, a tape recorder, and a can with baked beans), in the south of Oregon (USA), and posted the coordinates in the newsgroup. Soon the first website appeared for storing and communicating the locations of caches and the community rapidly grew. Interestingly, the activity was originally referred to as GPS stash hunt or gpsstashing; however, the name was changed to geocaching after a discussion in the gpsstash discussion group, because stash can have negative connotations. Today, nearly one million caches are stashed worldwide. The geocaching activity was "born" out of a technology friendly community (mostly male) that was interested in applying new technologies outdoors. Soon many different sorts and flavors were cached by many different kinds of user. In the following we describe the different types and sizes of geocaches to investigate what kind of caches users prefer.

2.2. Types and Sizes of Geocaches. Currently there are about two dozen different cache types. In the following we describe the most important and most accomplished ones. 


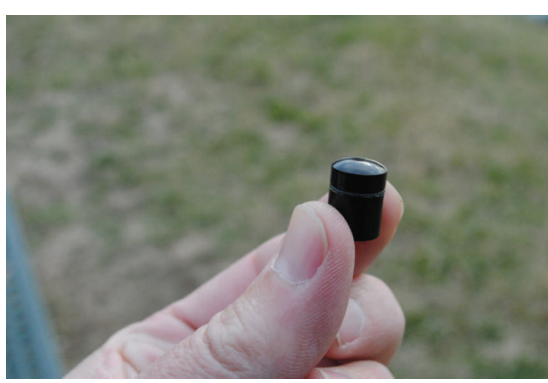

(a)

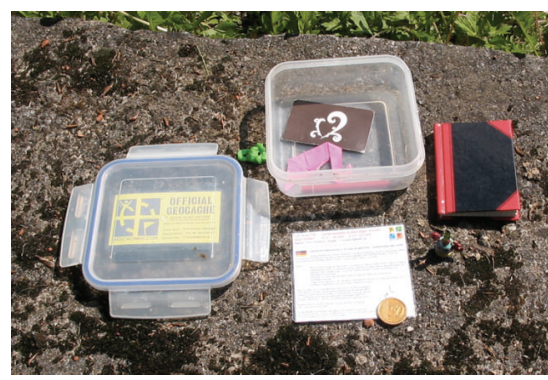

(b)

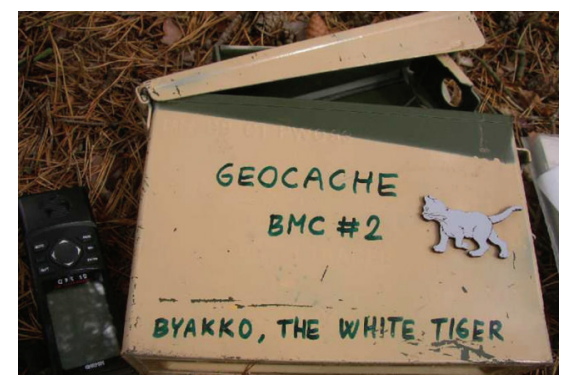

(c)

Figure 1: Geocache sizes: A microcache (a) (cc-zero), a small to regular sized cache (b) (by Lee Cannon licensed under the terms of the cc-by-sa-2.0), and a large cache (c) (cc-zero).

Traditional Caches. Like the first stash by Dave Ulmer this is the original cache type comprising a container and a log book.

Multicaches. A multicache involves two or more locations, the final location being a physical container. The most common multicaches provide a hint at the first location to guide the geocacher to the next one.

Mystery or Puzzle Caches. The "catch-all" of cache types are quite complex caches. A cache can involve brainteasers or puzzles that need to be solved correctly to determine the next or final coordinates of the next or final cache.

Letterbox (or Hybrid) Caches. Similar to the "catch-all" type in a letterbox (or hybrid) cache clues are used instead of coordinates to describe the next position of the cache.

Other Caches Types. There are many other different types of caches (or similar activities like Geohashing) listed on different geocaching websites, some of which are no longer available for creation on the different geocache websites while others are still young and not supported by all different geocache websites: Earthcache as defined by [19], (Mega-) Event Cache, Cache-In-Trash-Out, Virtual Cache, Webcam Cache, Locationless-Cache, and Wherigo. More information about the various different cache types are reported by [20].

Besides different cache types four main sizes of geocaches can be found: the micro ones are tiny and often just have a logbook and a pen and often film canisters are used for that size. Small caches are bigger than the micro ones and can have a volume of up to 1.5 litres. These caches can contain travel bugs or small bartering objects. Regular caches have a size of 1.5 litres up to 20 litres and can contain different types of bartering objects. Large caches are caches of more than 20 litres. Typical examples include rain barrels, boxings, suitcases, or even wardrobes. As reported by [20-22] they provide a good overview about these basic details to understand the conducted studies (see Figure 1).

2.3. Geocache Interaction Model. To understand the general procedure of geocachers, as well as the involved actors, we develop our geocache interaction model.

In general the geocaching process can be subdivided into consumption and creation. Consumption is the more common activity, but the hiding of caches is the fundamental basis of this activity as stated by [23]. Both activities can be done by geocachers with GPS enabled mobile devices. A specialised internet platform serves as a backbone for the geocachers and is used to store and exchange all needed information. Figure 2 illustrates the involved actors and shows the general actives as defined by Nielsen [24] and processes that are involved in the geocaching activity.

\section{Related Work}

Other researches have addressed the uniqueness of the geocaching activity in several ways: the quantitative studies $[11,17]$ were one of the first studies to look at motivations and interest of geocachers. O'Hara [2] investigated similar questions from a qualitative perspective with a rather small user set. It is also worthwhile mentioning the work of Kelley [25] who presents interesting anecdotes that raise a couple of questions related to the findings in this paper. Following the argument of O'Hara the basic contributions of her book are to underline the importance of the geocaching community by presenting certain unique attributes of the geocaching activity to characterise the geocaching community. GramHansen [3] studied geocaching from a persuasive perspective. Matherson [1] presents social studies on teacher's first use of geocaching in classrooms and shares perspectives from the teacher and her students on its value. Similar work was conducted by [26-28] to research the potentials of geocaching, for example, for mathematical learning in schools. Zan [5] investigated geocaching as basis for a road monitoring system. More recently Lam and Neustaedter [29] have studied how geocaching has also extended into virtual worlds like Second Life. Neustaedter et al. [30] also derived by studying geocaching, with a much smaller sample sizes $(n=3$, $n=185$ ), how to create scalable location-based games. Also similar research by Bellotti et al. [13] reflects on the motivations and challenges of designing mobile games for a challenging experience of the urban heritage.

In contrast to the related work so far no large-scale quantitative study has been carried out of a larger community, which could verify the findings of the prior pieces of work. This paper puts Chaves work on a much larger basis, trying to investigate in more depth the structure of the geocaching community. 


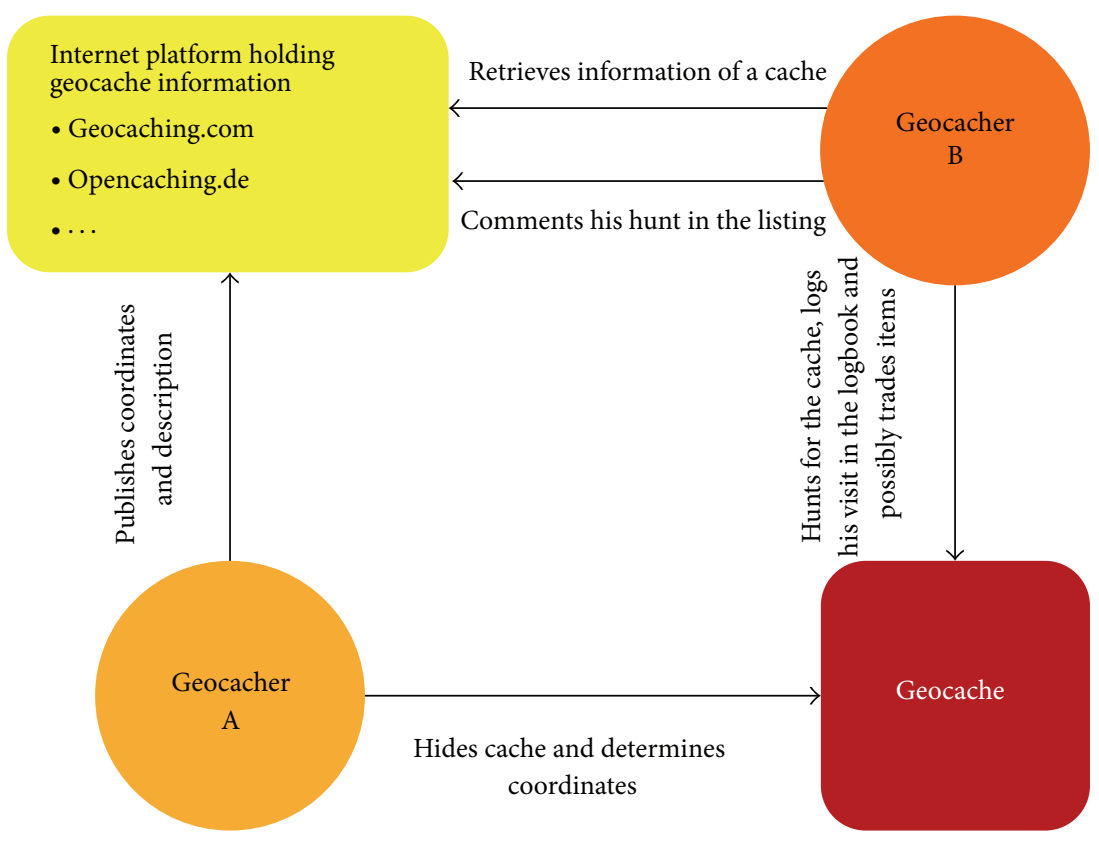

FIGURE 2: The geocache interaction model.

\section{User Studies}

In this section we will present the goals, methodology, and the results of the two studies we have conducted. Since we were interested in a large data set we decided to use online questionnaires, instead of conducting interviews, which would have been too time consuming and thus not feasible to conduct with the number of participants we had in mind.

4.1. Study Goal and Methods. The first questionnaire was designed to assess the structure of the German geocaching community and was addressed to the general German geocacher. The goal was to collect demographic data on sex, age, and income, to identify behavioural patterns and the motivation of geocachers as well as information on the tools they usually use. In the following we will refer to this study as the general study.

The second questionnaire was targeted at a specific region in Germany. For the length of the study we observed all successful geocaching attempts in a radius of $20 \mathrm{~km}$ around the city of Münster for 45 selected caches observing the digital logbooks of these caches on the web. An email questionnaire was sent to the finders of those particular caches. We were interested in learning how a certain region is perceived by geocachers and how this perception changed after the activity. We have chosen the region around Münster mainly because of its high density of caches and of personal interest, given that three of the authors come from that region and have experiences with geocaching themselves. The reminder of the paper part of the study will be called the regional study.

Both questionnaires have been distributed through internet platforms, which administrate geocaches. Every geocaching attempt requires the player to look up the coordinates and additional information on the cache online and is usually concluded by reporting the successful geocaching activity and which items have been removed and added to a particular cache. The use of these platforms allowed us to automate the process of data collection through questionnaires and resulted in high return rates. Instead of sending questionnaires via email (which can be blocked by filters or ignored by users), we decided to place the questionnaire on a dedicated server and placed a link to the survey on geocaching community web sites. Both questionnaires underwent a pretest with 30 subjects to ensure that all the questions were understandable and that the time to fill out the questionnaires was reasonable. The feedback was also used to refine the questions.

In order to motivate participants, they were given the opportunity to participate (after completion of the questionnaire) in a lottery and win small prizes, like Geocoins and other small geocaching artefacts.

4.1.1. General Study. The general study took place from May 21, 2007, to June 18, 2007. During these 28 days we had 3416 users visiting the start page of the questionnaire of which 2759 users started it. All of the submitted questionnaires were verified manually to identify partially filled-out questionnaires or nonserious attempts. Consequently, we used 1982 valid questionnaires for our further analysis. This equates to $71.83 \%$ of those that have started the questionnaire and $52.02 \%$ of those who visited the start page.

In turn $21.16 \%$ of the questionnaires were incomplete or obviously filled out at random. These results make us very confident that the questionnaire was easy enough to handle by most of the participants and that the design of the questionnaire had no major flaws. The return rate can be considered excellent, especially if compared to other internet studies by [31] or traditional "paper and mail" return rates as 
reported by [16]. The questionnaires have been advertised by different means.

(i) Firstly we have opened an email-thread on one of the major German discussion forums discussing the advantages of such a study.

(ii) Secondly we were able to place links on several web sites related to geocaching as much as on the start page of one of the major German geocaching-platforms http://www.opencaching.de/.

(iii) Furthermore we have distributed the link to the questionnaire through various mailing- and newslists.

(iv) Finally we selected on a random basis two geocaches in each federal state of Germany (32 caches in total) and asked (via email) all 1300 finders during the study period to answer the questionnaire.

The questionnaire consisted of 37 questions, a mix of closed and half-open questions, such as multiple-choice and ratings on a Likert-scale. A few open questions allowed the participants to provide comments and free thoughts. The questionnaire could be completed easily in 10 to 15 minutes.

4.1.2. The Regional Study. For the regional study we selected 45 geocaches in the region around the city of Münster. The selection was driven by the results of the pretest, which indicated a strong preference towards three types of geocaches: Traditional, Multi-, and Mystery cache (see above) of which 15 for each type have been selected on various geocaching platforms (i.e., http://www.geocaching.com/, http://www.opencaching.de/, and http://www.navicache .com). We tried to balance the age, the spatial distribution, and the vicinity to urban structure of the caches as effectively as possible.

We used the email contact utility of http://www.geocaching.com/ and http://www.opencaching.de/ to notify successful finders and ask them via email to participate in the study. We also visited all caches beforehand and placed little paper notes informing potential finders about the study goals. The study was conducted in the months of April and May 2007. During that period the caches in question were found 462 times. Finders have sent us 310 valid questionnaires. Some came from the same persons, since it was not very unlikely that one person found several of these caches during the study period.

The basic structure of the questionnaire was similar to the one used in the general study. However it was slightly shorter (28 questions) and was targeted explicitly at the finder of that geocache and was addressed to get more information about how a certain region is perceived by geocachers and how this perception changed after the activity. In consequence the questionnaire could be completed in about 5 to 10 minutes. Each questionnaire contained questions related to the particular geocache and the surroundings.

\section{Results}

This section reports the results of both studies. Given the high amount of returned questionnaires in relation to the assumed size of the overall community (approximately 10.000 geocachers in Germany in 2007) we consider the results as being highly valid and representative. We will concentrate on those results, which we believe could have an impact on the interaction of users with devices and the environment.

5.1. Results of the General Study. In the following we will discuss the main implications that can be drawn from the general study. We will give only a quick overview on the demoghrapic results and caching statistics, which we consider not highly relevant to the LBS community. Instead we will elaborate more on findings related to used devices and tools and motivation and interests of geocachers as well as on the context and properties of the caches.

5.1.1. Demographics. Geocaching appears to be mostly a male activity. $79.77 \%$ (1581 cases) of the questionnaires have been filled out by males and $20.23 \%$ by women (401). The age varied from 10 to 76 with a mean of 36.1 years $(\sigma=9.8)$. $90 \%$ of all participants were between 20 and 60 years old. More than three quarters (76.71\%) of the participants were married or living in similar relationships. More than $40 \%$ have reported to have children (41.21\%). A large amount of the participants has a university degree (41.07\%).

5.1.2. Caching Statistics. We asked participants to indicate how many geocaches they had found so far. The answers varied from 2 geocaches to 7600 geocaches, with a mean of 293.84 ( $\sigma=513.7)$. The median of found caches is 115 and $50 \%$ of the cases range from 30 to 325 found caches (see Figure 3). $33.20 \%$ of the participants had created caches themselves with a median of 2 caches per person. We also asked for how long participants would be active as geocachers. The results show that in the mean geocachers started approx. two years before the study period (1.7 years, $\sigma=1.25$ ). Our analysis also shows that $9.58 \%$ of the geocachers have been active for more than four years, $56.26 \%$ less than two years, and $78.21 \%$ for less than three years. We also asked about the frequency of their activity and the results show that $26.59 \%$ of geocachers are active more than once a week and $36.13 \%$ at least once a week, which means that $66.33 \%$ go out once a week to find a cache. We were also interested in learning about the amount of caches found during a single day trip and the majority (69.63\%) try to find between 2 to 5 caches. $22.15 \%$ concentrate on only one cache per trip and $8.22 \%$ usually aim to find 6 or more caches.

5.1.3. Used Devices. The activity of geocaching involves the use of a localisation device, usually based on the GPS. There exists a broad spectrum of such devices on the market ranging from simple GPS handheld receivers (which provide users with a geographic coordinate expressed in latitude and longitude) to personal digital assistant (PDA) and mobile phones that in principle can also provide cartographic information 


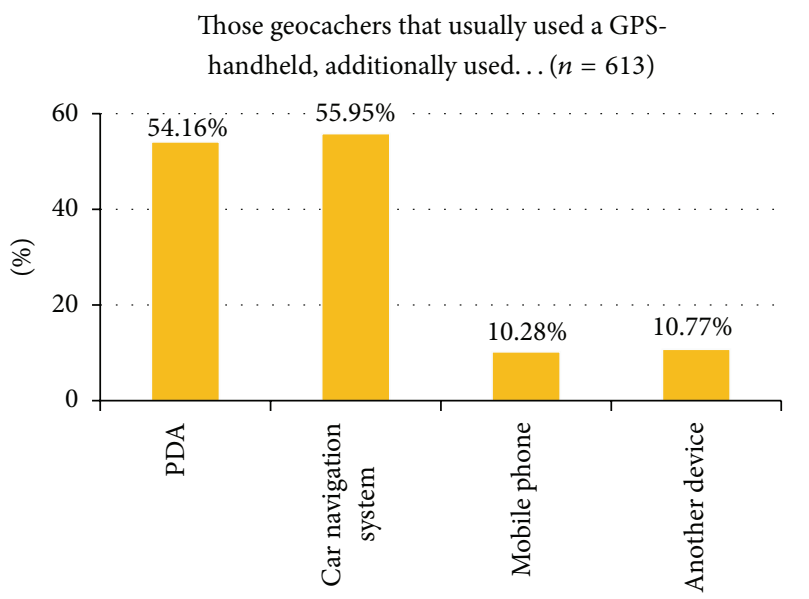

(a)

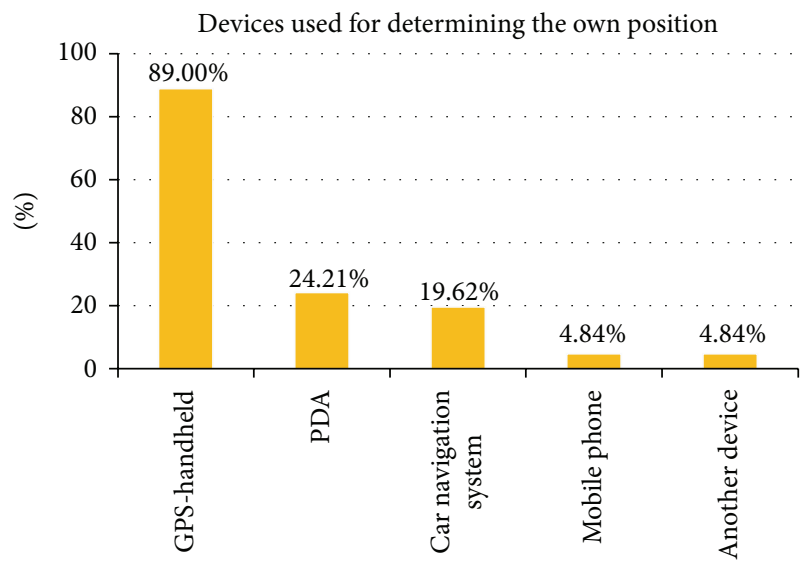

(b)

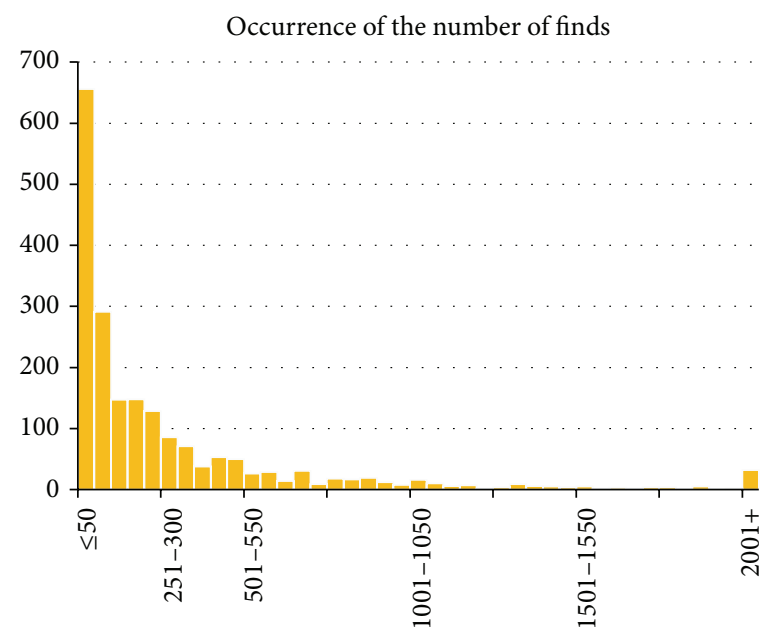

(c)

Figure 3: Histogram of numbers of caches found (a), devices used for determining the users position (b), and additional used devices and artefacts by the cachers (c).

on the screen. We were interested in learning from geocachers which devices they prefer for their activities.

As Figure 3 indicates, the large majority of geocachers use a simple GPS-device to localise themselves. 1764 participants (89\%) indicated this option. Roughly a quarter use a PDA (24.21\%) and $19.62 \%$ a mobile car navigation system. Not very surprisingly most of the geocachers used GPS-devices, since they are often ruggedised and some provide special support for geocachers and run long on batteries (e.g., the Garmin GPS 60 device series). The responses revealed that $34.75 \%$ of GPS-device users used additional devices: $54.16 \%$ of those used a PDA, $55.95 \%$ a mobile car navigation system, and $10.28 \%$ a mobile phone.

Participants were also allowed to name additional devices and tools and approximately $5 \%$ of the geocachers made use of a compass and many indicated paper-based material such as traditional maps as well as print-outs from web mapping services (such as Google Maps, Google Earth, or Open Street Maps). We asked participants whether they used digital mobile maps while geocaching, given that many devices support digital map formats. This was confirmed by
$70.33 \%$ of participants. Of those geocachers the rate of digital map usage was highest with PDA users $(87.30 \%)$, followed by mobile car navigation systems users $(81.20 \%)$ and mobile phone users $(76 \%)$. GPS devices were less used with digital maps $(68.60 \%)$. These results are very much in line with what we expected given the technological capabilities of each device category.

5.1.4. Media Types of Cache Descriptions. One important preparation step of geocaching is to lookup basic information about the cache (e.g., coordinates and degree of difficulty). Multicaches are often described by missions that have to be completed and mystery caches involve riddles that have to be solved in the field. Geocachers therefore need to bring this information along. When asked about the used media types, $90.72 \%$ of the participants reported to use paper printouts, $33.10 \%$ used their PDA, $8.17 \%$ mobile phones, and $7.52 \%$ reported to use other media types (participants were allowed to give multiple answers). The type of media was dependent on the cache type. Multicaches often require mathematical calculations, which are better supported by analogue paper 


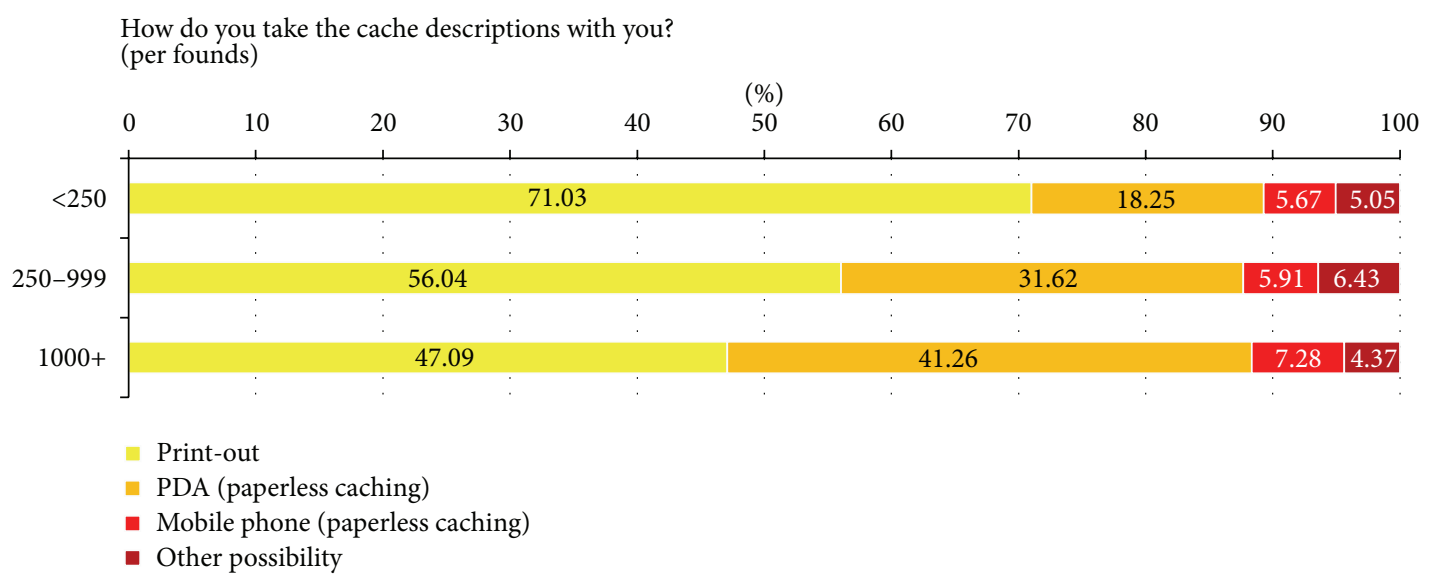

FIGURE 4: Ways of carrying around the cache description.

printouts than digital media. It appears that more active geocachers (more than 1000 caches found) use much more digital media than casual geocachers (less than 250 caches found). This relationship is expressed in Figure $4.71 .03 \%$ of the less frequent cachers used paper printouts while only $40.09 \%$ of the most frequent geocachers rely on analog media.

5.1.5. Social Context. As geocaching is a game that can be played together and simultaneously we were interested how often participants were conducting the activity with friends and family. The responses reveal that $23.16 \%$ of the participants usually find geocaches on their own, $47.3 \%$ reported that they would equally geocache on their own as well as with others, and $29.41 \%$ stated that they would carry out this activity only together with others. The 1523 participants of the two latter categories (all geocachers that like to be active in a group) were additionally asked with whom they usually find caches. $60.93 \%$ reported to go out very frequently with their partners and $20.75 \%$ said that they would sometimes do it. $26 \%$ of the participants reported to frequently take the whole family on a geocache search. Also of interest was the answer to the question of how often nongeocaching friends have been taken on a trip (64.28\%).

Overall it can be stated that geocaching is a social activity that brings together family members, friends, and other geocachers.

5.1.6. Selection Principles. We were interested in learning how geocachers select a cache that they would like to visit. To investigate this question we asked the participants to choose amongst three statements: (a) "I usually stick to my favourite cache-type and avoid other types", (b) "I make a choice depending on my current interests and needs," and (c) "I have no dedicated preference, I just want to find all caches in my surroundings." The results split the geocachers into two categories: $47.78 \%$ were purely interested in finding all caches in their regional proximity (option (c)), and $34.66 \%$ agreed to option (b), indicating that they make an informed decision based on their current interests and needs. Only 9.33\% were focusing on one particular cache type (option (c)). $8.53 \%$ reported completely different selection principles in the free text section of the questionnaire. For example, participants reported that the decision, which cache to select, depends on the company and the group. For example, with family members they would carefully reflect the degree of difficulty (option (b)), while when on their own they would just try to find as many caches as possible (option (c)).

5.1.7. Motivation. We tried also to shed light on the motivations of geocachers and offered participants nine statements that they were asked to rate on a four-point Likert-scale (see Figure 5). According to the results, the main motivation for the activity of geocaching is the possibility to be in nature (nearly everybody either agreed or totally agreed with the corresponding statement). Although as we discussed earlier, most of the participants enjoy geocaching with others, this seems to be less important. Getting more familiar with the regional environment as well as being able to discover new places is another important motivation.

5.2. Results of the Regional Study. In the following we will discuss the main implications that can be drawn from the regional study which was based on questionnaires that were sent directly to finders of 45 randomly selected caches in the region of Münster.

\subsubsection{Properties and Characteristic of a Geocache That Attract} Cachers. What makes a geocache attractive to the users? Of course, the properties of geocaches and the environments where it is located are important for the attractiveness for the geocachers. Besides the types and the size of a cache (as described above) many different, often abstract properties of the cache can make a cache attractive to the user. Figure 6 summarizes these additional properties a cache can have. The most important factor was the fact that the cachers will experience something new and learn something about the environment. Nearly all $(94.70 \%)$ of the users agree and more than the half strongly agree (57.37\%). They liked caches where they can learn something new and caches with intellectual challenges (e.g., more complicated multicaches). Besides that fact, geocaches that enable the cachers learn 


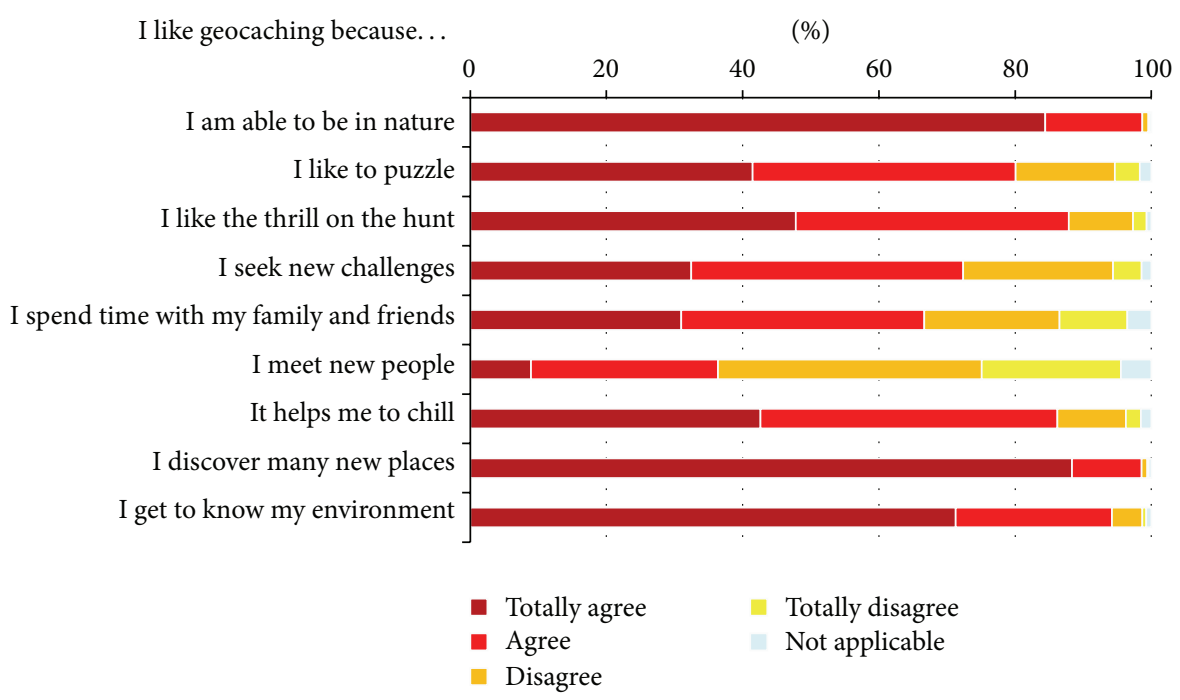

Figure 5: Motivation of geocachers.

Which characteristics should a cache have? I like a geocache when..

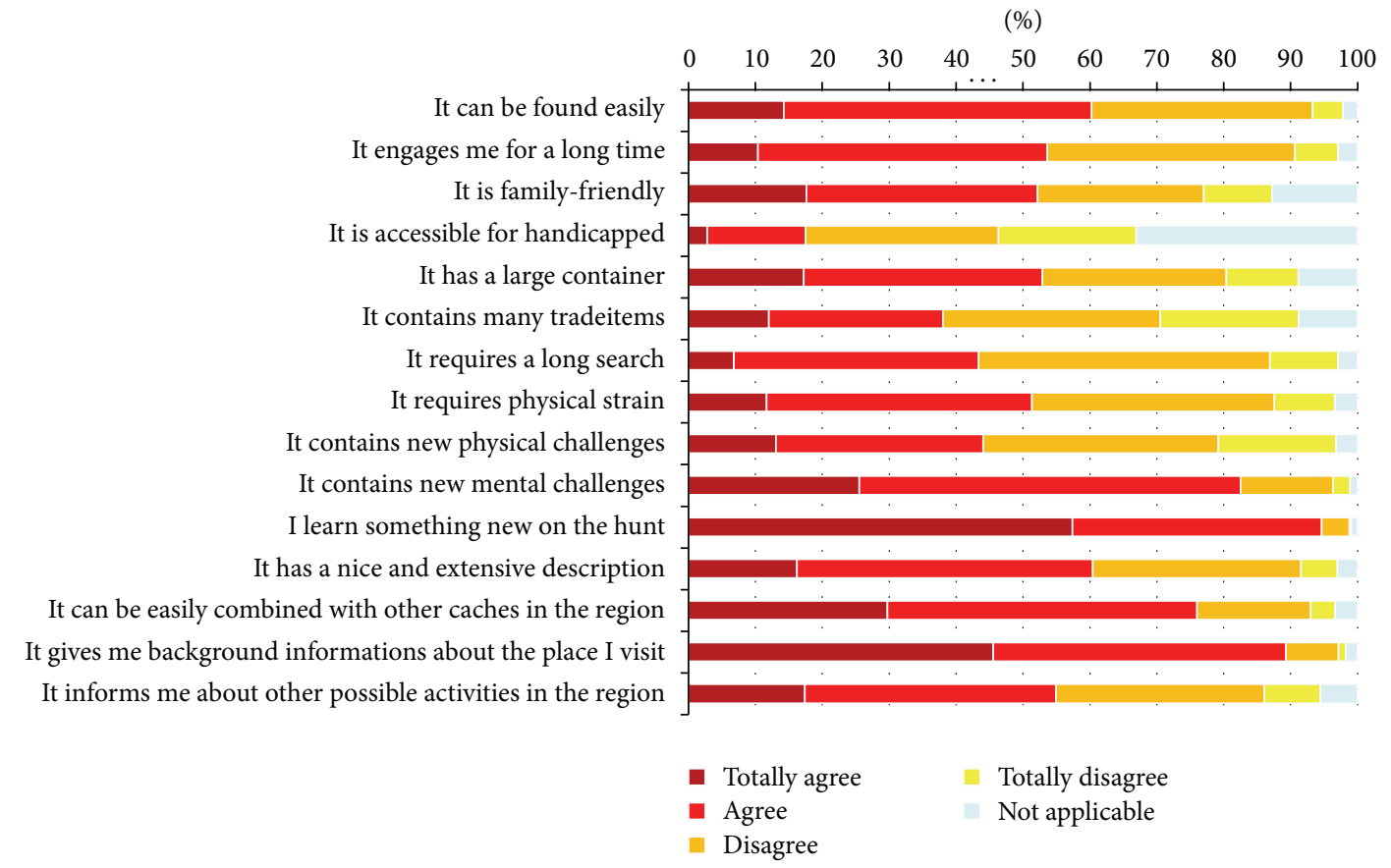

FIGURE 6: Properties and characteristic of a geocache that attract cachers.

something interesting about the environment were appealing to the participants.

Complex and detailed cache descriptions with tips for activities after the caching activity also enhanced the attractiveness of a cache. A high search complexity in the form of a multicache was a positive property of a cache for about $43.39 \%$ of the participants. In contrast to that about $60.24 \%$ liked caches, which can be found easily. More than the half (51.32\%) liked physical strain during the caching activity, but limited to activities that they are used to. $44.05 \%$ do not want to experience different physical strain. Besides those more abstract properties of a geocache, $52.93 \%$ liked big cache sizes but just $38.04 \%$ liked caches with lots of bartering objects. All results are summarized in detail in Figure 6.

5.2.2. Properties and Characteristic of the Environment That Attract Cachers. In contrast to the properties of the cache also the (abstract or concrete) properties of the environment are important factors for the attractiveness of a cache, because as described previously, most cachers want to learn something new on the hunt. Again nearly all participants (98.69\%) like caches in an attractive and interesting landscape. Caches 
in urban environments (as opposed to caches in nature) received the worst ratings. 50.51\% liked cached which could be combined with other leisure activities in the area but interestingly just $20.18 \%$ wanted to have restaurants nearby the caches.

Another interesting finding was that the access of the starting point by the public transporting system was only mentioned by $24.27 \%$ as a desired property. $86 \%$ of the geocachers approach the starting point of a cache by car and like the actual starting point to be easily accessible by foot. Other caches at nearby locations also enhance the attractiveness of a cache. It is interesting to see that cachers with higher income more often agreed that they will visit the region again for other activities (biking, swimming, and restaurant).

\section{Discussion}

Overall it turned out that geocaching is very attractive to people with a secure lifestyle, which usually undertake this hobby together. Essential aspects of motivation are sojourning in nature and becoming acquainted with unknown places. The image that the geocachers have of a region is in most cases positively influenced by geocaching. Consequently, these places are sought after for recreational activities. The result of this study provides an accurate picture of the very multifaceted German-speaking geocaching community. We believe that it is important to preserve this dataset and the findings to later generate an accurate historic picture over the changes in the geocaching community in the last decade.

In this section we discuss some of the results of our representative study and compare our findings to previous work, that is, the work of $[2,11,17]$. We can mostly confirm the demographic data of Chavez, although our study area is twice as big and the amount of returned questionnaires 15 times as large. Our data indicates slightly more male geocachers than Chavez has reported. We have looked at a variety of additional factors including the educational level of participants and we found that geocachers have an above average level of education.

We have made use of the community platforms to spread our questionnaire and developed a new method to investigate caches within a certain region. By addressing successful geocachers in a certain region via email, we achieved an extremely high return rate of more than $60 \%$ with very relevant responses. In line with O'Hara and Chavez, we can therefore confirm that one of the main motivations of geocachers is to be out in the nature and to discover new places and locations. We could also confirm that geocachers usually perform their activities together with others and could, for the first time, quantify this quite precisely. In line with O'Hara we assumed that this would be also one of the major motivations for geocachers in general. Surprisingly, it played a less important role than expected. One explanation could be that the attractiveness of geocaching is the fact that it is a socially more acceptable use of technology and therefore gives highly active geocachers the possibility for frequent geocaching trips together with friends and family. This hypothesis is supported by the fact that many geocachers are accompanied by nongeocachers during their activity.
We could also show that there are two major categories of geocachers that split the community: the collector and the gourmet.

Geocachers of the first category are mainly interested in making as many caches of a certain region as possible; O'Hara [2] had identified a similar category. The second category consists of geocachers that choose on a very individualistic basis their next caches. These findings are significant for informing the design and placement of new caches. For collectors, new caches need to be placed in sparse cache areas, while gourmets ask for exciting locations or difficult riddles. Besides consumption, O'Hara highlights the importance of creation of geocaches for the 14 participants of his study. We could not find much evidence for that particular claim. Our data shows that only one-third of the participants have ever created a geocache on their own. Similar to other communities (such as the Wikipedia community) consumption is clearly the more common observed behaviour.

Besides the demographic data and the social dimension using GPS for the geocache activity we also examined the devices used. Although simpler GPS-devices were mostly used it was surprising how many users still used PDAs as well as mobile car navigation systems in the year 2007, as already first smartphones existed. In addition geocaching novices often took a printout description of the cache with them. Next generation of geocache interfaces should allow the combination of paper-based media in combination with new devices such as GPS equipped mobile phone.

The fact that a large fraction of geocachers uses more than one device also surprised us and next generation interfaces should combine the all different functions necessary for a successful geocaching experience. Moreover rural areas can profit from geocachers and try to attract wealthy geocachers targeting the geocache websites and internet communities. Additionally geocaching, as a technology driven activity, can support helping people to corporealize.

\section{Conclusion and Further Work}

In this paper, we have presented the first large-scale quantitative survey of the German geocaching community. We have partly confirmed the studies of $[2,11,17]$. The geocaching community is still growing (but the growth is slowing down) and compared to O'Hara we found that the consumption of caches is more important for most of the users than the creation. The geocache activity is an interesting research field for the HCI community, because the activity was created by early adopters of a new technology. Therefore it could be used as an example for similar novel activities that are centred around technology (e.g., the use of activity sensing devices for fitness [32]).

Compared to Chavez we examined a larger area, but it would be interesting to investigate cultural differences on a world wide scale or investigate the geocache activities in developing countries, where internet and mobile devices are not so commonly used.

Geocaching now also hits its peaks and user activities are starting to cool down. It would be interesting to see if the "hype" will completely seep away in the next 5 years, 
because more and more geocachers become pure consumers or the cache density saturates in nature. We are interested in comparing the act of geocache creation to those of other web 2.0 creation processes, such as authoring Wikipedia articles studied by [33] and to investigate the balance of creators and consumers.

While the main contribution of the paper is the presentation of a rich quantitative survey, we think that our analysis grounds related work effectively and places certain earlier findings from geocaching studies into the right perspective. Two observations from our data set are particularly relevant to this regard.

(i) Firstly, the part of our data set relating to consumption (of the experience) versus creation (of a geocache) seems to conform to Nielsen's 90-9-1 theory relating towards the general pattern of user generated content creation, descripted in [24] and also investigated by [34] in more detail, which stipulates that only $1 \%$ of online community users will contribute regularly, 9\% will contribute intermittently, and the remainder will "lurk", consuming content without contributing.

(ii) Secondly, the data shows some interesting facts, such that geocachers are often accompanied by nongeocachers and family members, but being with others seems not to be the primary motivation for the activity.

From a technological point of view it is interesting to see which media are currently used to bring the cache description into the field. We think that the use of a combination of traditional and modern media is especially interesting.

\section{Conflict of Interests}

We also declare that there is no conflict of interests regarding the publication of this paper.

\section{Acknowledgments}

The authors would like to thank all their colleagues, especially Keith Cheverst and Robert Schleicher, for their comments and ideas on various iterations of this paper.

\section{References}

[1] L. Matherson, V. Wright, C. Inman, and E. Wilson, "Get up, get out with geocaching: engaging technology for the social studies classroom," Social Studies Research and Practice, vol. 3, no. 3, 2008.

[2] K. O'Hara, "Understanding geocaching practices and motivations," in Proceedings of the 26th Annual SIGCHI Conference on Human Factors in Computing Systems (CHI '08), pp. 1177-1186, Florence, Italy, April 2008.

[3] L. B. Gram-Hansen, "Geocaching in a persuasive perspective," in Proceedings of the 4th International Conference on Persuasive Technology (Persuasive '09), p. 34, April 2009.
[4] M. Lochrie, K. Lund, and P. Coulton, "Community generated location based gaming," in Proceedings of the 24th BCS Interaction Specialist Group Conference (BCS '10), pp. 474-478, 2010.

[5] B. Zan, T. Sun, M. Gruteser, and Y. Zhang, "ROME: road monitoring and alert system through geocache," in Proceedings of the IEEE International Symposium on Parallel and Distributed Processing, Workshops and Phd Forum in conjunction with EuroPar (IPDPSW'10), April 2010.

[6] K. Lund, M. Lochrie, and P. Coulton, "Enabling emergent behaviour in location based games," in Proceedings of the 14th International Academic MindTrek Conference: Envisioning Future Media Environments (MindTrek'10), pp. 78-85, Tampere, Finland, October 2010.

[7] A. E. Bowser, D. L. Hansen, J. Raphael et al., "Prototyping in PLACE: a scalable approach to developing location-based apps and games," in Proceedings of the 31st Annual SIGCHI Conference on Human Factors in Computing Systems: Changing Perspectives (CHI '13), pp. 1519-1528, Paris, France, May 2013.

[8] T. Vartiainen and T. Tuunanen, "Co-creation of value for ITenabled services: a case of geocaching," in Proceedings of the 46th Annual Hawaii International Conference on System Sciences (HICSS '13), pp. 1093-1102, Maui, Hawaii, USA, January 2013.

[9] J. Procyk, C. Neustaedter, C. Pang, A. Tang, and T. K. Judge, "Exploring video streaming in public settings: shared geocaching over distance using mobile video chat," in Proceedings of the SIGCHI Conference on Human Factors in Computing Systems (CHI '14), pp. 2163-2172, 2014.

[10] S. Greenberg and B. Buxton, "Usability evaluation considered harmful (some of the time)," in Proceedings of the SIGCHI Conference on Human Factors in Computing Systems (CHI '08), pp. 111-120, April 2008.

[11] D. Chavez, I. Schneider, and T. Powell, “The social-psychology of a technology driven outdoor trend: geocaching in the USA," in Proceedings of the Hawaii International Conference on System Sciences (HICSS '04), 2004.

[12] L. Barkhuus, M. Chalmers, P. Tennent et al., "Picking pockets on the lawn: the development of tactics and strategies in a mobile game," in Proceedings of the International Conference on Ubiquitous Computing, pp. 358-374, 2005.

[13] F. Bellotti, R. Berta, A. De Gloria, E. Ferretti, and M. Margarone, "Designing mobile games for a challenging experience of the urban heritage," in Proceedings of the Annual International Conference on Parallel Processing, pp. 1129-1136, 2003.

[14] S. Benford, A. Crabtree, M. Flintham et al., "Can you see me now?" ACM Transactions on Computer-Human Interaction, vol. 13, no. 1, pp. 100-133, 2006.

[15] O. Jones, M. Williams, and C. Fleuriot, "a new sense of place?' mobile wearable information and communications technology devices and the geographies of urban childhood," Children's Geographies, vol. 1, no. 2, pp. 165-180, 2003.

[16] J. McGonigal, Why I Love Bees: A Case Study in Collective Intelligence Gaming, The John D. and Catherine T. MacArthur Foundation Series on Digital Media and Learnin, The MIT Press, Cambridge, Mass, USA, 2007.

[17] D. Chavez, R. Courtright, and I. Schneider, "Over the river and through the woods," Parks \& Recreation, vol. 39, no. 4, pp. 6872, 2004.

[18] B. Parkinson and J. Spilker, Global Positioning System: Theory and Applications, AIAA, 1996.

[19] G. Lewis, "Eearthcaching an adventure game with an earthy twist," GSA Today, vol. 15, no. 1, pp. 38-38, 2005. 
[20] J. W. Peters, Complete Idiot's Guide to Geocaching, Alpel Publishing, 2004.

[21] M. Dyer, The Essential Guide to Geocaching: Tracking Treasure with Your GPS, Fulcrum Publishing, 2004.

[22] E. Sherman, Geocaching: Hike and Seek with Your GPS, Apress, 2004.

[23] B. Schlatter and A. Hurd, "Geocaching-21st-century hide-andseek," Journal of Physical Education, Recreation \& Dance, vol. 76, no. 7, pp. 28-32, 2005.

[24] J. Nielsen, Participation Inequality: Encouraging more Users to Contribute. Jakob Nielsens Alertbox 9, Jakob Nielsen's Alertbox 9, 2006.

[25] M. Kelley, Local Treasures: Geocaching Across America, Center for American Places, University Presses Marketing, 2005, [distributor].

[26] L. Bragg, Y. Pullen, and M. Skinner, "Geocaching: a worldwide treasure hunt enhancing the mathematics classroom," in Proceedings of the 47th Annual Conference of the Mathematical Association of Victoria (MAV'10), pp. 54-62, 2010.

[27] P. Hauselt and J. Helzer, "Integration of Geospatial Science in Teacher Education," Journal of Geography, vol. 111, no. 5, pp. 163172, 2012.

[28] J. A. Olson, "Geography, GIS and gaming: learning tools or just for fun?" Journal of Map \& Geography Libraries, vol. 8, no. 3, pp. 290-294, 2012.

[29] C. Lam and C. Neustaedter, "Explorations of geocaching in the virtual world of second life," in Proceedings of the International Conference on Computer Supported Cooperative Work Companion, pp. 179-182, February 2013.

[30] C. Neustaedter, A. Tang, and T. K. Judge, "Creating scalable location-based games: lessons from Geocaching," Personal and Ubiquitous Computing, vol. 17, no. 2, pp. 335-349, 2013.

[31] C. Cook, F. Heath, and R. L. Thompson, "A meta-analysis of response rates in Web- or internet-based surveys," Educational and Psychological Measurement, vol. 60, no. 6, pp. 821-836, 2000.

[32] T. Fritz, E. M. Huang, G. C. Murphy, and T. Zimmermann, "Persuasive technology in the real world: a study of long-term use of activity sensing devices for fitness," in Proceedings of the SIGCHI Conference on Human Factors in Computing Systems (CHI '14), pp. 487-496, 2014.

[33] N. Miller, "Wikipedia and the Disappearing "Author"'” ETC.: A Review of General Semantics, vol. 62, no. 1, pp. 37-41, 2005.

[34] C. Boulaire and B. Cova, "The dynamics and trajectory of creative consumption practices as revealed by the postmodern game of geocaching," Consumption Markets \& Culture, vol. 16, no. 1, pp. 1-24, 2013. 

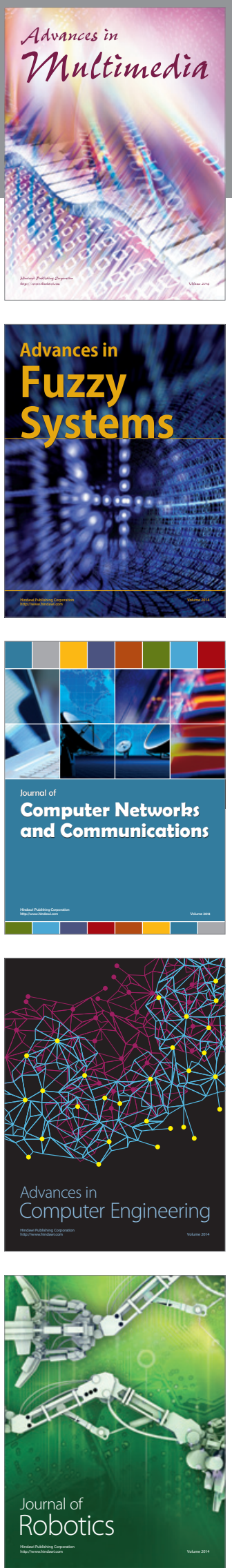

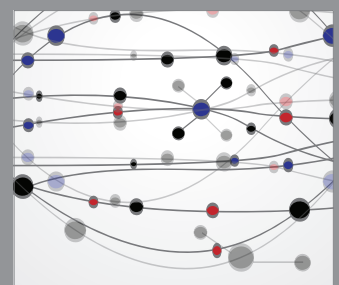

The Scientific World Journal
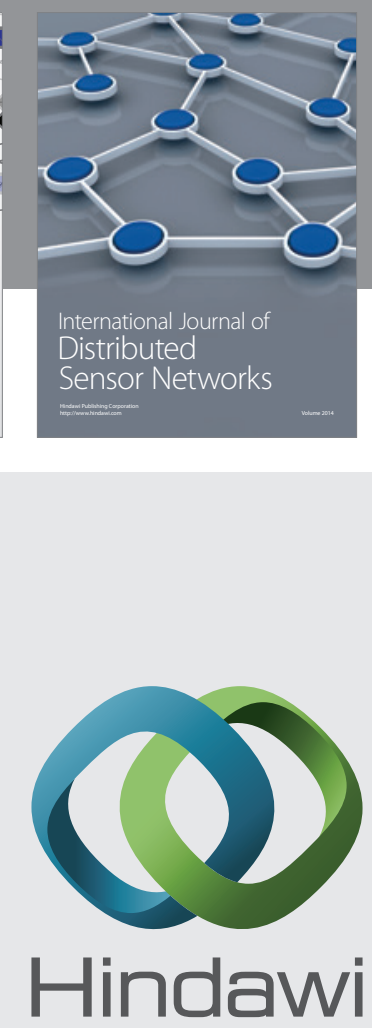

Submit your manuscripts at

http://www.hindawi.com
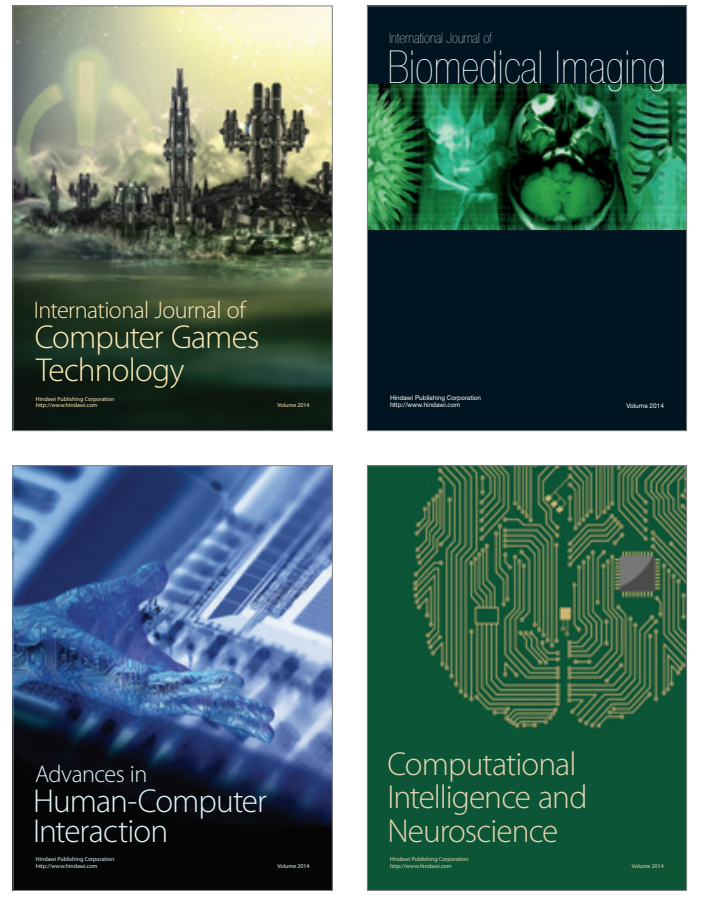
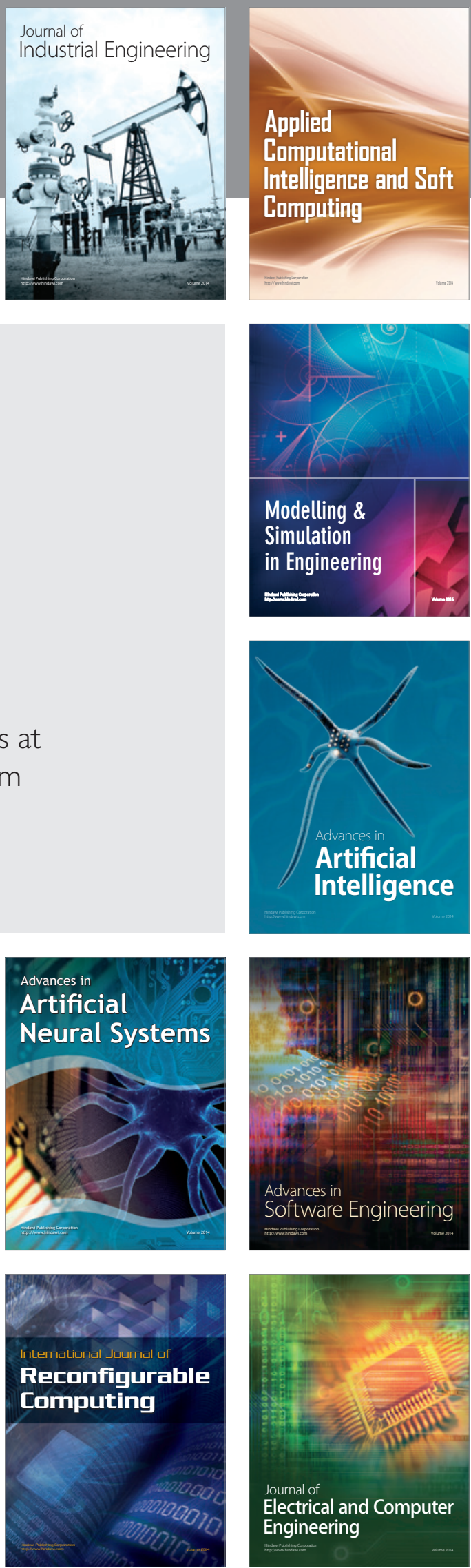